\title{
Inhibition of Hepatic Stellate Cell Activation Suppresses Tumorigenicity of Hepatocellular Carcinoma in Mice
}

Min-Jung Kang, ${ }^{*}$ Soovin Lee, ${ }^{\dagger}$ Usuk Jung, ${ }^{*}$ Chanchal Mandal, ${ }^{*}$ Heekyung Park, ${ }^{*}$ William G. Stetler-Stevenson, ${ }^{\star}$ Young-Sik Kim, Ji Wook Moon, "Sun-Hwa Park, "and Junseo $0 h^{*}$

From the Department of Biomedical Science, * Korea University Graduate School, Seoul, Korea; the Laboratory Animal Research Center, ${ }^{\dagger}$ the Department of Pathology, ${ }^{\S}$ and the Department of Anatomy, ${ }^{\circledR}$ College of Medicine, Korea University, Seoul, Korea; and the Extracellular Matrix Pathology Section, ${ }^{\ddagger}$ Laboratory of Pathology, National Cancer Institute, National Institutes of Health, Bethesda, Maryland

\author{
Accepted for publication \\ August 6, 2021. \\ Address correspondence to \\ Junseo Oh, Ph.D., Department \\ of Biomedical Science, Korea \\ University Graduate School, \\ Seoul 02841, Korea. E-mail: \\ ohjs@korea.ac.kr.
}

\begin{abstract}
Transdifferentiation (or activation) of hepatic stellate cells (HSCs) to myofibroblasts is a key event in liver fibrosis. Activated HSCs in the tumor microenvironment reportedly promote tumor progression. This study analyzed the effect of an inhibitor of HSC activation, retinol-binding protein-albumin domain III fusion protein (R-III), on protumorigenic functions of HSCs. Although conditioned medium collected from activated HSCs enhanced the migration, invasion, and proliferation of the hepatocellular carcinoma cell line Hepa-1c1c7, this effect was not observed in Hepa-1c1c7 cells treated with conditioned medium from R-III-exposed HSCs. In a subcutaneous tumor model, larger tumors with increased vascular density were formed in mice transplanted with Hepa-1c1c7+HSC than in mice transplanted with Hepa-1c1c7 cells alone. Intriguingly, when Hepa-1c1c7+HSC-transplanted mice were injected intravenously with R-III, a reduction in vascular density and extended tumor necrosis were observed. In an orthotopic tumor model, co-transplantation of HSCs enhanced tumor growth, angiogenesis, and regional metastasis accompanied by increased peritumoral lymphatic vessel density, which was abolished by R-III. In vitro study showed that R-III treatment affected the synthesis of pro-angiogenic and anti-angiogenic factors in activated HSCS, which might be the potential mechanism underlying the R-III effect. These findings suggest that the inhibition of HSC activation abrogates HSC-induced tumor angiogenesis and growth, which represents an attractive therapeutic strategy. (Am J Pathol 2021, 191: 2219-2230; https://doi.org/10.1016/j.ajpath.2021.08.004)
\end{abstract}

Cancers develop in complex tissue environments, which is essential for sustained growth, invasion, and metastasis. ${ }^{1}$ Tumor angiogenesis is an essential process for tumor progression, and lymphatic vessels provide an alternate route for tumor cell dissemination. ${ }^{2}$ The tumor microenvironment (TME) comprises a mass of heterogeneous cell types, among which the two most prominent types of protumorigenic cells are cancer-associated fibroblasts (CAFs) and tumor-associated macrophages. ${ }^{3}$ CAFs, also called myofibroblasts, are reportedly associated with the progression of several types of cancers, and can originate as a result of the activation of resident fibroblasts, bone marrow-derived fibrocytes, epithelial cells, endothelial cells, or from certain specialized cells such as stellate cells (SCs) in the pancreas and liver. ${ }^{4}$ The presence of activated SCs has been shown in the stroma surrounding cancer cells, and bidirectional interactions between SCs and cancer cells, by which tumor-derived factors activate SCs, and, in turn, activated SCs promote metastatic growth. ${ }^{5,6}$ Conditioned media from activated SCs promotes the proliferation, migration, and invasion of tumor cells in vitro, and co-transplantation of

Supported by a National Research Foundation of Korea grant funded by the Ministry of Science and Information and Communications Technology (ICT) grant NRF-2017M3A9C8031617 (J.O.).

Disclosures: None declared.

Current address of M.-J.K., MDimune, Inc., Research Institute, Seoul, Korea; of C.M., Biotechnology and Genetic Engineering Discipline, Khulna University, Khulna, Bangladesh. 
these activated SCs and tumor cells into mice resulted in an enlarged tumor mass that correlated with enhanced angiogenesis. $^{7,8}$

Hepatic stellate cells (HSCs) are pericytes residing in the space of Disse between the sinusoidal endothelial cells and the parenchymal cells, and constitute $5 \%$ to $10 \%$ of the total number of cells in the liver. ${ }^{9}$ In normal liver, HSCs maintain a nonproliferative, quiescent phenotype and store approximately $80 \%$ of vitamin A (retinol) in the whole body as retinyl esters in lipid droplets in the cytoplasm. In response to fibrogenic stimuli, HSCs become activated, transdifferentiating from vitamin A-storing cells to myofibroblast-like cells. ${ }^{10}$ Upon activation, HSCs lose cytoplasmic vitamin A-containing lipid droplets, proliferate vigorously, and produce a large amount of extracellular matrix proteins. When cultured on plastic, HSCs undergo spontaneous activation in vitro. Activation of HSCs is a widely accepted key event in liver fibrosis, which is characterized by excessive accumulation of extracellular matrix proteins. ${ }^{11}$ Cirrhosis is the advanced stage of liver fibrosis and is the leading risk factor for the development of hepatocellular carcinoma (HCC). ${ }^{12}$ Cells resembling HSCs were isolated from the pancreas in the late $1990 \mathrm{~s},{ }^{13}$ and these pancreatic stellate cells also play a central role in pancreatic fibrogenesis in a manner similar to HSCs. ${ }^{14}$

Albumin is the most abundant plasma protein with a mol. wt. of approximately $66 \mathrm{kDa}$ produced in the liver. ${ }^{15}$ It is composed of three homologous domains (I to III) and performs a variety of functions. A previous study showed that albumin was expressed in quiescent SCs, but not in activated SCs, and that its forced expression in activated SCs induced the phenotypic reversion to fat-storing, early activated cells. ${ }^{16}$ Building on these results, a recombinant fusion protein (designated R-III; mol. wt., approximately 45 $\mathrm{kDa}$ ) was developed as an antifibrotic agent, in which the domain III of albumin was fused to the C-terminus of retinol-binding protein. ${ }^{17}$ Retinol-binding protein was adopted for targeted delivery to SCs because the protein and its membrane receptor STRA6 coordinate the cellular uptake of retinol into HSCs. ${ }^{18} \mathrm{~A}$ follow-up study showed that $\mathrm{R}$-III inhibited SC activation in vitro and reduced liver and kidney fibrosis in vivo. ${ }^{19-21}$ In this study, the effect of R-III on the protumorigenic functions of activated HSCs was examined, and R-III was found to suppress HSC-induced HCC angiogenesis and growth.

\section{Materials and Methods}

Male BALB/c mice and female BALB/c-nu/nu mice were purchased from Orient Bio, Inc. (Sungnam, Korea) and maintained under temperature-, humidity-, and lightcontrolled conditions. All animal experimental protocols were approved by the institutional review board and performed in accordance with the NIH Guide for the Care and Use of Laboratory Animals. ${ }^{22}$ Mouse hepatoma Hepa-1c1c7 cells were obtained from the ATCC (Rockville, MD) and cultured in Dulbecco's modified Eagle's medium (DMEM) supplemented with $10 \%$ fetal bovine serum. The fusion protein R-III (Supplemental Figure S1) was synthesized using a previously described method. ${ }^{19}$

\section{Isolation of Mouse HSCS}

HSCs were isolated from male BALB/c mice (age, 14 weeks) as described previously ${ }^{21}$ and cultured in DMEM supplemented with $10 \%$ fetal bovine serum. The purity of the HSCs was assessed by microscopic observation. The HSCs harvested on day 1 after seeding were used as preactivated HSCs. Cells were passaged before reaching $70 \%$ confluence in the primary culture and used as activated HSCs. The activation status of the HSCs was assessed on the basis of their increased expression of $\alpha$-smooth muscle actin ( $\alpha$-SMA) and collagen type I, as well as through their morphologic changes.

\section{Collection of Conditioned Medium}

HSCs after passage 1 (activated HSCs) were incubated for 24 hours in low-serum DMEM (containing $0.5 \%$ fetal bovine serum and $0.75 \%$ bovine serum albumin) in the presence or absence of R-III $(0.25 \mu \mathrm{mol} / \mathrm{L})$. Conditioned medium from HSCs (HSC-CM) was centrifuged for 10 minutes at $750 \times g$, passed through a sterile filter, and frozen at $-80^{\circ} \mathrm{C}$ for future use. Low-serum DMEM without cells incubated for 24 hours in cell culture dishes was used as the negative control.

\section{Monolayer Wound Healing Assay}

HSCs were grown to confluency in 24-well plates and mechanically scratched using a sterile $200-\mu \mathrm{L}$ pipet tip. The media and the dislodged cells were aspirated and replaced by $\mathrm{CM}$. After incubation at $37^{\circ} \mathrm{C}$ for 24 or 48 hours, the cells were photographed using a microscope in five random fields. The width of the wounded cell monolayers was measured from the images, and the rates of migration were calculated using the following formula: $\%$ migration = (initial scratch wound width - scratch wound width at time point $\mathrm{X}$ )/initial scratch wound width $\times 100$.

\section{Cell Invasion Assay}

Biocoat Matrigel-coated invasion chambers (BD Biosciences, Bedford, MA) were used to examine cell invasiveness. Briefly, Hepa-1c1c7 cells $\left(2.5 \times 10^{4}\right)$ in $500 \mu \mathrm{L}$ serum-free medium were seeded into the upper chamber, and $700 \mu \mathrm{L} \mathrm{CM}$ was added to the lower chamber. The cells were allowed to invade the Matrigel for 20 hours at $37^{\circ} \mathrm{C}$. The noninvading cells on the upper surface of the membrane were removed with a cotton swab. Cells were fixed with $4 \%$ paraformaldehyde, stained with $0.5 \%$ crystal violet, and 
air-dried. Invading cells were counted for each membrane in four adjacent microscopic fields.

\section{Cell Proliferation}

Hepa-1c1c7 cells $\left(8 \times 10^{3}\right.$ cells/well $)$ were seeded into 96 well plates, incubated at $37^{\circ} \mathrm{C}$ for 24 hours, and then treated with CM. After 24 hours of treatment, cell viability was measured using the Cell Counting Kit-8 (Dojindo Laboratories, Tokyo, Japan).

\section{Mouse HCC Subcutaneous Implantation Model}

Six-week-old female BALB/c-nu/nu mice were injected subcutaneously in the flank with $1 \times 10^{6}$ Hepa- 1 c1c7 cells alone $(n=6)$ or in combination with $2 \times 10^{5}$ activated HSCs $(n=12)$. Hepa-1c1c7+HSC-transplanted mice were divided randomly into 2 groups ( $n=6$ per group) and injected via the tail vein with saline or R-III $(30 \mu \mathrm{g})$ once every 3 days, starting on day 6 after tumor cell transplantation. Mice were euthanized 22 days after injection. Tumor growth was monitored twice a week with electronic calipers, and the tumor volume was calculated using the following standard formula: tumor volume $\left(\mathrm{mm}^{3}\right)=$ longest diameter $\times(\text { shortest diameter })^{2} \times 0.5$. Hematoxylin and eosin-stained slides of tumors were subjected to reading and determination of areas of necrosis, and necrotic area was calculated with ImageJ software version 1.53a (NIH, Bethesda, MD; http://imagej.nih.gov/ ij). All experiments were performed in duplicate.

\section{Mouse Hepatocellular Carcinoma Orthotopic Implantation Model}

Six-week-old female BALB/c-nu/nu mice were used for implantation. Orthotopic implantation was performed as previously described. ${ }^{23}$ Briefly, after anesthetizing the mice $(n=18)$, the median lobe of the liver was exposed and a piece of sterile Gelfoam (Technew, Rio de Janeiro, Brazil) was placed to maintain the surface moisture in the liver and to prevent leakage and bleeding. Small-volume Matrigel suspensions $(20 \mu \mathrm{L})$ containing $1 \times 10^{6} \mathrm{Hepa}-1 \mathrm{c} 1 \mathrm{c} 7$ cells alone $(n=6)$ or in combination with $2 \times 10^{5}$ HSCs $(n=12)$ were injected into the subcapsular region of the liver parenchyma in the median lobe. The mice injected with Hepa-1c1c7+HSC were divided randomly into 2 groups ( $n=6$ per group) and injected via tail vein with saline or R-III $(30 \mu \mathrm{g})$ once every 3 days, starting on day 6 after tumor transplantation. Mice were euthanized 35 days after surgery and weighed. The livers were harvested, and the total liver tumor volume was calculated as the sum of the volumes of all tumors; tumor volume $\left(\mathrm{mm}^{3}\right)$. To assess the metastatic spread of green fluorescent protein (GFP)-labeled Hepa-1c1c7 cells, lung and pancreas were examined ex vivo using the EVOS FL imaging system (Thermo Fisher Scientific, Bothell, WA).
Generation of a Stable GFP-Expression Hepa-1c1c7 Cell

Hepa-1c1c7 cells were transfected with pEGFP vector using Lipofectamine 2000 (Invitrogen, Carlsbad, CA) and subject to drug selection by the addition of G418 to the medium. The high-GFP-expressing cell among stably transfected cells was selected and used for the experiments.

\section{Immunohistochemistry and Immunofluorescence}

Sections $(5-\mu \mathrm{m}$ thick) of formalin-fixed, paraffin-embedded tissues were prepared and subjected to immunohistochemistry with the antibodies listed in Table 1 . Seven randomly selected high-power microscopic fields were photographed, and immunohistochemistry staining intensities were quantified using a three-tiered system of none-to-weak, moderate, and strong immunoreactivity, as described previously. ${ }^{24}$ For immunofluorescence, after antibody incubation, nuclei staining was performed with DAPI. The cells were observed under a Leica TCS SP8 microscope and the fluorescent intensity quantification was analyzed using LasX software (Leica, Mannheim, Germany).

\section{Quantitative Real-Time PCR}

Total RNA was prepared using TRIzol (Ambion, Austin, TX), and was used to synthesize the cDNA. Real-time PCR was performed on an ABI QuantStudio 3 Real-Time PCR System (Thermo Fisher Scientific, Waltham, WA). To control for variations in the reaction, the PCR products were normalized against the mRNA levels of glyceraldehyde 3phosphate dehydrogenase. The primers used are listed in Table $2 .^{25-28}$

Table 1 Primary Antibodies Used in This Study

\begin{tabular}{|c|c|c|}
\hline Method & $\begin{array}{l}\text { Primary } \\
\text { antibody }\end{array}$ & $\begin{array}{l}\text { Company, catalog no. } \\
\text { (location) }\end{array}$ \\
\hline \multirow[t]{3}{*}{ Immunohistochemistry } & CD31 & $\begin{array}{l}\text { Cell Signaling, } 77699 \\
\text { (Beverly, MA) }\end{array}$ \\
\hline & LYVE-1 & $\begin{array}{c}\text { Novus Biological, NB100- } \\
725 \text { (Centennial, C0) }\end{array}$ \\
\hline & Ki-67 & $\begin{array}{l}\text { Abcam, ab16667 } \\
\text { (Cambridge, MA) }\end{array}$ \\
\hline \multirow[t]{3}{*}{ Immunofluorescence } & $\alpha-S M A$ & Abcam, ab32575 \\
\hline & Cygb/STAP & $\begin{array}{l}\text { Generous gift from Dr. } \\
\text { Norifumi Kawada (Osak } \\
\text { City University) }\end{array}$ \\
\hline & PDGFR $\alpha$ & Abcam, ab93531 \\
\hline \multirow[t]{2}{*}{ Western blot } & Histidine $^{49}$-tag & $\begin{array}{l}\text { AB Frontier, LF-MA-20209 } \\
\text { (Seoul, Korea) }\end{array}$ \\
\hline & $\alpha$-tubulin & Cell Signaling, 2125 \\
\hline
\end{tabular}

$\alpha$-SMA, $\alpha$-smooth muscle actin; Cygb/STAP, cytoglobin/stellate cell activation-associated protein (Cygb/STAP); LYVE-1, lymphatic vessel endothelial receptor-1; PDGFR $\alpha$, platelet-derived growth factor receptor alpha. 


\section{Western Blot Analysis}

Cell lysates were prepared for analysis by electrophoresis and immunoblotting as described previously. ${ }^{19}$ The primary antibodies used are listed in Table 1.

\section{Proteome Profiler Angiogenesis Antibody Array}

The proteome profiler mouse angiogenesis antibody array was performed following the manufacturer's instructions (R\&D Systems, Minneapolis, MN).

\section{Establishment of Primary Culture from Tumor Tissue and CAF Isolation}

Primary culture was established as previously described. ${ }^{29}$ Briefly, tumor tissues were dissected from the livers of Hepa-1c1c7+HSC-injected mice and minced with a curved scissor. After enzymatic digestion with collagenase, the tissue/media mixture was centrifuged at $450 \times g$ for 5 minutes at $4^{\circ} \mathrm{C}$ and resuspended in red blood cell lysis buffer. After centrifugation, cell pellets were resuspended in DMEM supplemented with $10 \%$ fetal bovine serum and seeded on culture plates to establish primary cultures. For CAF isolation, cell pellets were resuspended in $0.5 \mathrm{~mL}$ fluorescence-activated cell sorting buffer. After removing $0.05 \mathrm{~mL}$ for use as unstained control, the rest of the solution was incubated with anti-phycoerythrin-conjugated platelet-derived growth factor receptor alpha (PDGFR $\alpha$ ) antibody (ab93531, $10 \mu \mathrm{g} / \mathrm{mL}$; Abcam, Cambridge, MA) for 1 hour at $4^{\circ} \mathrm{C}$. The cells were washed with fluorescence-activated cell sorting buffer and the PDGFR $\alpha$-positive cells were sorted using BD FACS Aria III (BD Biosciences, San Jose, CA). These cell-sorting experiments were performed using the sort precision mode set to purity mode to exclude droplets containing unwanted cells.

\section{Statistical Analysis}

Results are expressed as means $\pm \mathrm{SD}$. A two-way analysis of variance with the Dunnett multiple comparison test was used for in vitro experiments. Data from in vivo studies were analyzed by either the one-way ANOVA, Wilcoxon ranksum test, or the Kruskal-Wallis test, followed by the Dwass-Steel-Critchlow-Fligner multiple comparison. A $P$ value $<0.05$ was considered statistically significant.

\section{Results}

Effect of R-III on the Protumorigenic Functions of Activated HSCs with Respect to the HCC Cell Line Hepa-1c1c7 in Vitro

Because activated HSCs in the TME promote tumor progression, ${ }^{6}$ the study investigated whether the recombinant
Table 2 Primers Used in This Study

\begin{tabular}{|c|c|c|}
\hline Gene name & Sequence & Reference \\
\hline \multirow[t]{2}{*}{ ACTA2 } & F: 5'-CCAGCACCATGAAGATCAAG-3' & \\
\hline & R: 5'-TGGAAGGTAGACAGCGAAGC-3' & \\
\hline \multirow[t]{2}{*}{ COL1A1 } & F: 5'-CGACCTCAAGATGTGCCACT-3' & \\
\hline & R: 5'-CTTGGTTAGGGTCGATCCAG-3' & \\
\hline \multirow[t]{2}{*}{ GFAP } & F: 5'-CACGAACGAGTCCCTAGAGC-3' & \\
\hline & R: 5'-GCAAGTGCCTCCTGGTAACT-3' & \\
\hline \multirow[t]{2}{*}{$P 21$} & F: 5'-CAGATCCACAGCGATATCCA-3' & \\
\hline & R: 5'-AGACAACGGCACACTTTCGT-3' & \\
\hline \multirow[t]{2}{*}{ TIMP1 } & F: 5'-GCATCTGGCATCCTCTTGTT-3' & \\
\hline & R: 5'-TGGGGAACCCATGAATTTAG-3' & \\
\hline \multirow[t]{2}{*}{ TIMP2 } & F: 5'-TTCTTGACATCGAGGACCCG-3' & \\
\hline & R: 5'-AGCGTGAACCCACTTGGATG-3' & \\
\hline \multirow[t]{2}{*}{ VEGFR2 } & F: 5'-TGGGCAGTCAAGTCCGAATC-3' & \\
\hline & R: 5'-TTGGACTCAATGGGCCTTCC-3' & \\
\hline \multirow[t]{2}{*}{ PDGFD } & F: 5'-GATGACTACTTTGTGGCAAAACC-3' & \\
\hline & R: 5'-GTGACTGATTCCCAGTTGGTC-3' & \\
\hline \multirow[t]{2}{*}{ PDGFC } & F: 5'-GCCCGAAGTTTCCTCATACA-3' & 25 \\
\hline & R: 5'-ACACTTCCATCACTGGGCTC-3' & \\
\hline \multirow[t]{2}{*}{ VEGFA } & F: 5'-AGTCCCATGAAGTGATCAAGTTCA-3' & 25 \\
\hline & R: 5'-ATCCGCATGATCTGCATGG-3' & \\
\hline \multirow[t]{2}{*}{ VEGFD } & F: 5'-GAACACAAGCACCTCCTACAT-3' & 26 \\
\hline & R: 5'-CACAGGCTGGCTTTCTACTT-3' & \\
\hline \multirow[t]{2}{*}{ CXCL12 } & F: 5'-GAGCCAACGTCAAGCATCTG-3' & 27 \\
\hline & R: 5'-CGGGTCAATGCACACTTGTC-3' & \\
\hline \multirow[t]{2}{*}{ ANGPT1 } & F: 5'-GGGGGAGGTTGGACAGTAA-3' & 28 \\
\hline & R: 5'-CATCAGCTCAATCCTCAGC-3' & \\
\hline
\end{tabular}

$F$, forward; $R$, reverse.

fusion protein R-III suppresses the protumorigenic functions of HSCs. HSCs were isolated from the liver of BALB/c mice by enzyme perfusion/density gradient centrifugation and culture-activated. In agreement with previous studies, ${ }^{17}$ real-time PCR showed that the mRNA expression of $\alpha$-SMA and collagen type I, well-known markers of HSC activation, ${ }^{30,31}$ was greatly increased in HSCs after passage 1 (activated HSCs) compared with that in HSCs on day 1 after seeding (pre-activated HSCs). This was decreased in HSCs after R-III treatment (Figure 1A). By contrast, the mRNA expression of glial fibrillary acidic protein, a marker of quiescent HSCs, ${ }^{32}$ was decreased in activated HSCs. CM was collected from activated HSCs with or without R-III treatment for 24 hours, and Hepa-1c17 cells (HCC cell line) were treated with CM. CM from activated HSCs enhanced the migration, invasion, and proliferation of Hepa-1c1c7 cells (Figure 1, B-D), similar to that observed in different HCC cell lines. ${ }^{7,33,34}$ In contrast, CM from R-III-treated HSCs did not exert significant stimulatory effects on tumor cell migration, invasion, or proliferation. The expression of cellular senescence markers, ${ }^{35}$ such as p21, tissue inhibitor of metalloproteinase-1 (TIMP-1), and TIMP-2, was not changed significantly, thereby indicating that this is perhaps not a result of tumor cell senescence by $\mathrm{CM}$ from R-III-treated HSCs (Figure 1E). The change in growth 

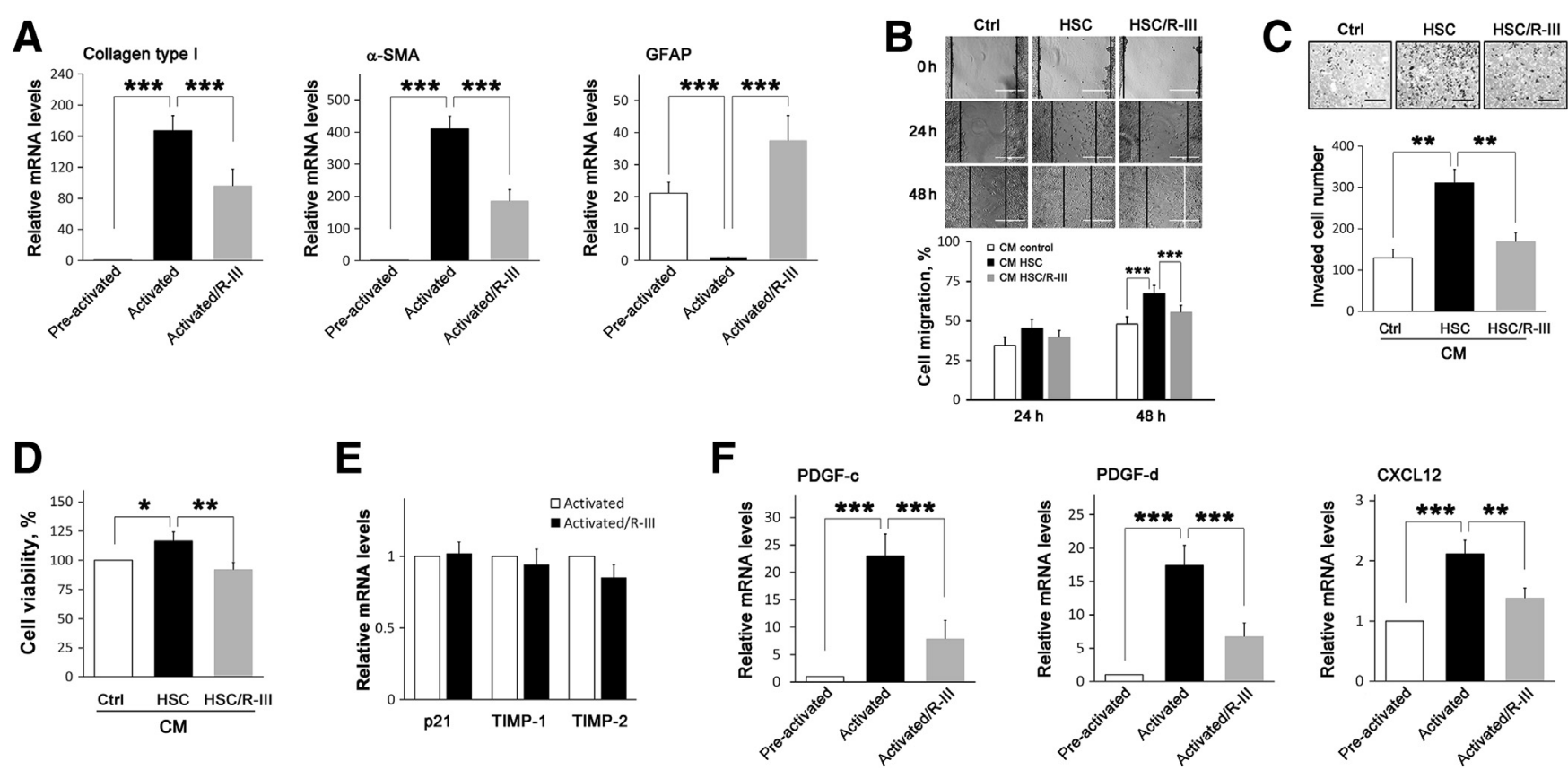

Figure 1 R-III reduces the protumorigenic effects of activated hepatic stellate cells (HSCs) in vitro. A and F: Total RNA was isolated from HSCs on day 1 after seeding (pre-activated), and from HSCs after passage 1 (activated) with or without R-III treatment ( $0.25 \mu$ mol/L) for 24 hours. Real-time PCR was used to analyze mRNA levels of collagen type I, $\alpha$-smooth muscle actin ( $\alpha$-SMA), and glial fibrillary acidic protein (GFAP) (A), and platelet-derived growth factor (PDGF)-c, PDGF-d, and CXCL12 (F). B-D: Conditioned medium (CM) was collected from activated HSCs with or without R-III treatment, and was used to stimulate the Hepa-1c1c7 cells. The migratory and invasive abilities of the cells were analyzed using a monolayer wound healing assay (B) and a Matrigel invasion assay (C), respectively. B: Black lines indicate the margins of migrating cells. D: The Cell Counting Kit-8 was used to analyze cell proliferation. E: Hepa-1c1c7 cells were incubated with CM from activated HSCs that were treated with or without R-III for 24 hours, and the mRNA levels of p21, tissue inhibitor of metalloproteinase-1 (TIMP-1), and TIMP-2 were analyzed by real-time PCR. Data are expressed as means \pm SD for three independent experiments. ${ }^{*} P<0.05,{ }^{*} P<0.01$, and ${ }^{* *} P<0.001$ by two-way analysis of variance (ANOVA) with the Dunnett multiple comparison test. Scale bars: $400 \mu \mathrm{m}$ (B); 200 $\mu \mathrm{m}(\mathrm{C})$. Ctrl, control.

factor expression was assessed because of previous reports indicating that activated HSCs stimulate the migration, invasion, and proliferation of cancer cells by producing an increased number of growth factors and cytokines. ${ }^{6,8,36}$ The mRNA expression of PDGF-c, PDGF-d, and CXCL12 (also known as stromal cell-derived factor 1) was found to be up-regulated during HSC activation, but was downregulated in response to R-III (Figure 1F). It should be noted that R-III did not enter Hepa-1c1c7 cells or affect their growth (Supplemental Figure S2), which is consistent with the previous report that R-III does not enter carcinoma cells. ${ }^{17}$ These findings show that R-III-mediated inhibition of HSC activation is accompanied by reduced expression of PDGF-c, PDGF-d, and CXCL12, which correlates with a decrease in the protumorigenic functions of HSCs.

\section{Effect of R-III on the Protumorigenic Functions of HSCs in the Subcutaneous Tumor Model}

To explore the antitumor activity of R-III in vivo, a subcutaneous xenograft model was used. Hepa-1c1c7 cells $\left(1 \times 10^{6}\right.$ cells $)$ were transplanted either alone or in combination with activated HSCs $\left(2 \times 10^{5}\right.$ cells $)$ into the flanks of nude mice (ratio of Hepa-1c1c7:HSCs, 5:1), and the Hepa-1c1c7+HSC-transplanted mice were injected intravenously with saline or R-III once every 3 days, starting on day 6 after transplantation. Palpable tumors were not detected in mice injected with HSCs alone. Although the Hepa-1c1c7 cells alone formed tumors, the tumors were larger when these cells were transplanted along with HSCs (Figure 2, A-C). Importantly, intravenous administration of R-III induced large areas of hemorrhagic necrosis within the tumors, which was accompanied with reduced tumor weight (Figure 2, C-E). It is well known that tumor necrosis results from tissue hypoxia that occurs during tumor progression owing to rapid tumor growth and an inadequate blood supply. Because R-III did not induce apoptotic cell death (terminal deoxynucleotidyl transferase-mediated dUTP nick-end labeling assay, data not shown), the study tested whether RIII could affect tumor angiogenesis. Consistent with previous reports, ${ }^{33,34}$ co-transplantation with HSCs significantly promoted tumor angiogenesis and proliferation, as shown by immunohistochemistry for CD31 and Ki-67, a cellular proliferation marker (Figure 2, F and G). However, this effect of activated HSCs was abrogated by R-III administration. Real-time PCR analysis showed that the expression level of vascular endothelial growth factor (VEGF) receptor-2 in tumors roughly paralleled the intensity of CD31 immunostaining (Figure $2 \mathrm{H}$ ). 

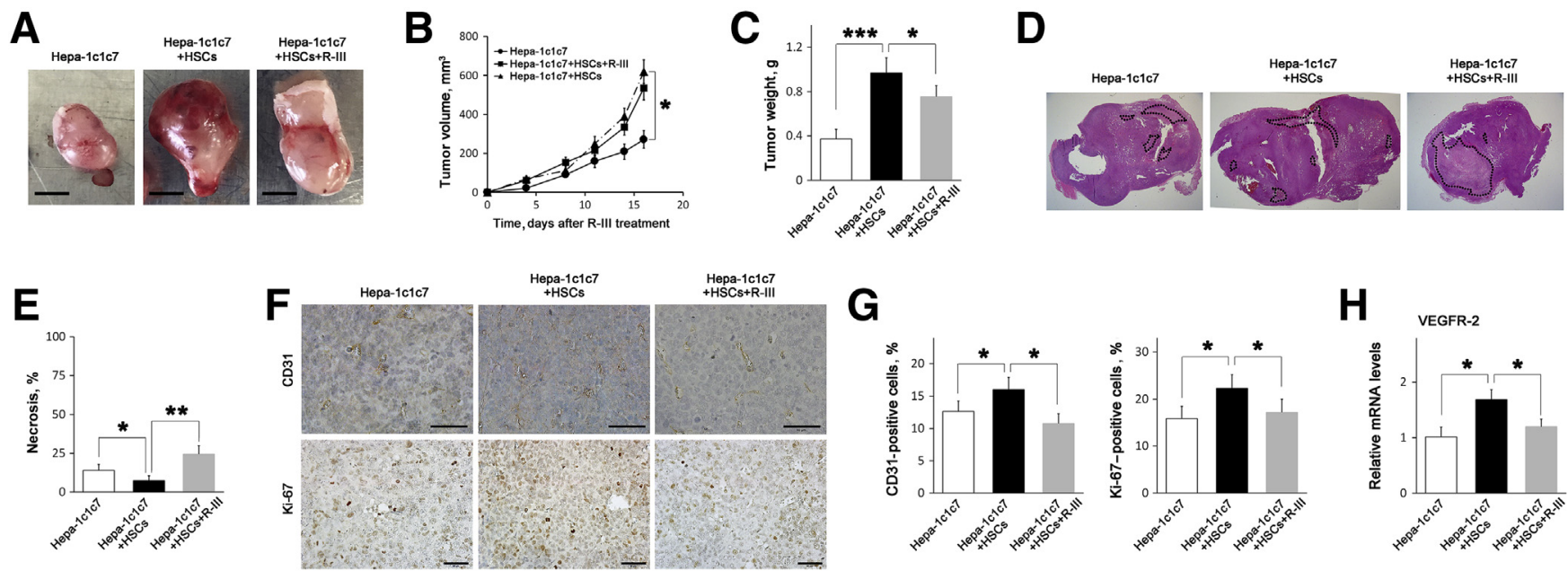

Figure 2 R-III induces necrosis in subcutaneous tumors. A: Representative images of subcutaneous tumors in mice transplanted with Hepa-1c1c7 alone or with Hepa-1c1c7+hepatic stellate cells (HSCs) in the presence or absence of R-III treatment. B: Tumor volumes were measured at the indicated time points. C: Tumor weights were determined after being harvested from the mice 22 days after tumor transplantation. $\mathbf{D}$ and E: Tumor sections were stained with hematoxylin and eosin, and the necrotic areas are indicated by black dashed lines and measured. R-III induces large areas of hemorrhagic necrosis within tumors. F and G: Tumor sections were subjected to immunohistochemistry with CD31 and Ki-67 antibodies. G: Semiquantitative analysis of each immunostaining. H: Total RNA was extracted from the tumors, and the expression level of vascular endothelial growth factor receptor (VEGFR)-2 was analyzed by realtime PCR. Data are expressed as means \pm SD by one-way analysis of variance $(\mathbf{C})$ and by the Kruskal-Wallis test, followed by Dwass-Steel-Critchlow-Fligner multiple comparison (H). ${ }^{*} P<0.05,{ }^{*} P<<0.01$, and ${ }^{* * *} P<0.001$. Scale bars: $5 \mathrm{~mm}(\mathbf{A}) ; 50 \mu \mathrm{m}(\mathbf{F})$.

\section{Effect of R-III on the Protumorigenic Functions of HSCs in the Orthotopic Tumor Model}

To assess the growth and metastasis of HCC cells, an orthotopic HCC model in nude/athymic mice was established using GFP-expressing HCC reporter cell lines. Hepa1c1c7 cells, either alone or in combination with activated HSCs, were transplanted directly into the median liver lobe of nude mice. When co-transplanted with both Hepa-1c1c7 and HSCs, the orthotopic tumors grew larger and bloody ascites developed in all mice 3 to 5 weeks after transplantation (Figure 3A). When evaluating the metastatic spread, GFP-positive cells were detected in the enlarged lymph nodes-near the pancreas-only in the cotransplanted mice, which indicates occurrence of regional metastasis (Figure 3). Lung metastasis was not detected. On the other hand, mice treated with R-III had smaller tumors, developed lesser ascites, and had fewer GFP-positive lymph nodes, indicating that R-III inhibited HSC-induced HCC tumorigenicity. There were no significant differences in the body weights of treatment groups (Supplemental Figure S3).

\section{Inhibition of Tumor Angiogenesis and} Lymphangiogenesis by R-III

Because lymphangiogenesis is another mode of vascularization in tumors and lymphatic vessels represent an alternate route for dissemination of cancer cells, ${ }^{37}$ sections of orthotopic tumors were immunostained with antibodies against lymphatic vessel endothelial receptor-1 (LYVE-1), a lymphatic endothelial cell marker, as well as CD31.
Intratumoral and peritumoral blood vessel density, and peritumoral lymphatic vessel density, were increased significantly in tumors from Hepa$1 \mathrm{c} 1 \mathrm{c} 7+\mathrm{HSC}-$ transplanted mice compared with that in tumors from mice that received Hepa-1c1c7 alone (Figure 4). The occurrence of intratumoral lymphatic vessels was rare. However, R-III administration abrogated the effect of HSCs on vascular density.

\section{Regulation of Pro-Angiogenic and Anti-Angiogenic Factors in HSCs by R-III}

The in vivo results from both subcutaneous and orthotopic tumor models showed that co-transplantation with HSCs significantly promoted tumor angiogenesis, which was abolished by R-III administration. Because activated HSCs reportedly release multiple pro-angiogenic factors into the TME, ${ }^{34,36,38,39}$ the expression of these factors was assessed by real-time PCR. It was found that, similar to the expression of PDGF-d and CXCL12 (Figure 1E), the expression of VEGF-d and angiopoietin-1 was upregulated during $\mathrm{HSC}$ activation, but down-regulated in response to R-III (Figure 5A). The expression of VEGF-a was increased slightly during HSC activation, but was not altered significantly with R-III. To determine the secretion of angiogenesis-related factors, CM from activated HSCs treated with or without R-III was analyzed by a proteome profiler angiogenesis antibody array. Intriguingly, R-III treatment enhanced the secretion of 12 proteins, such as ADAMTS1, angiogenin, Cyr61, endostatin, IGFBP-3, CXCL1, CXCL4, CXCL10, MMP-9, PDGF-AA, 
A
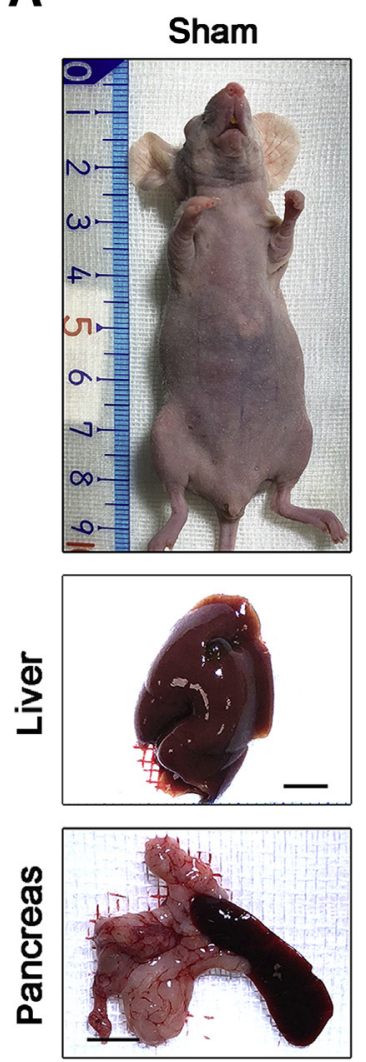

Hepa-1c1c7
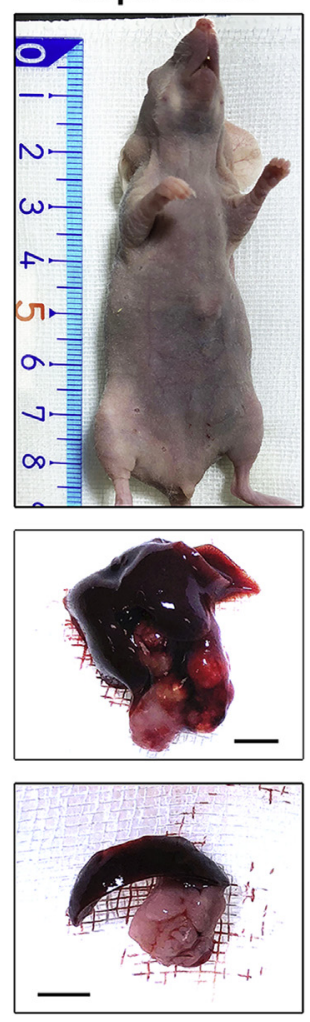

Hepa-1c1c7 +HSCs
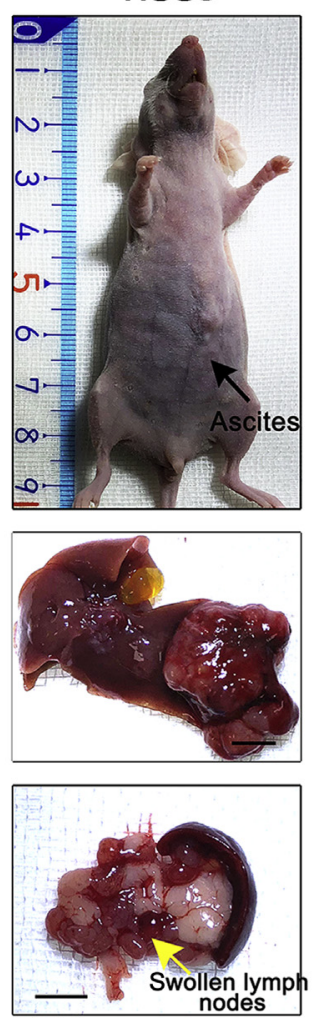

Hepa-1c1c7

+ HSCs+R-III
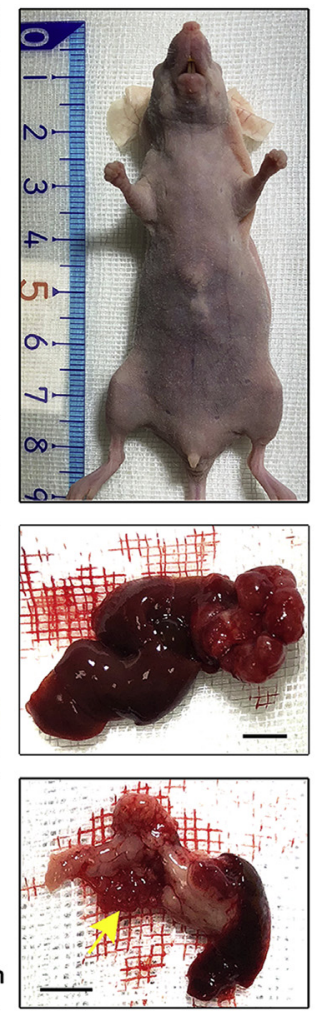

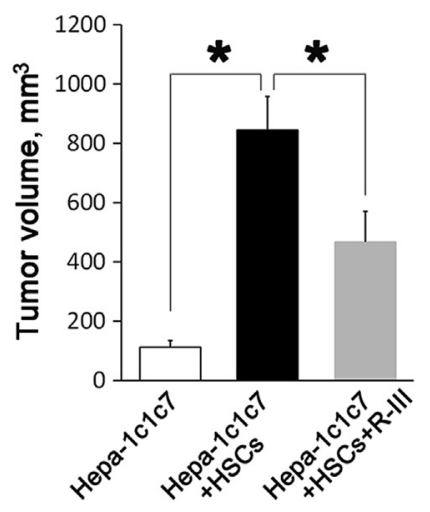

B
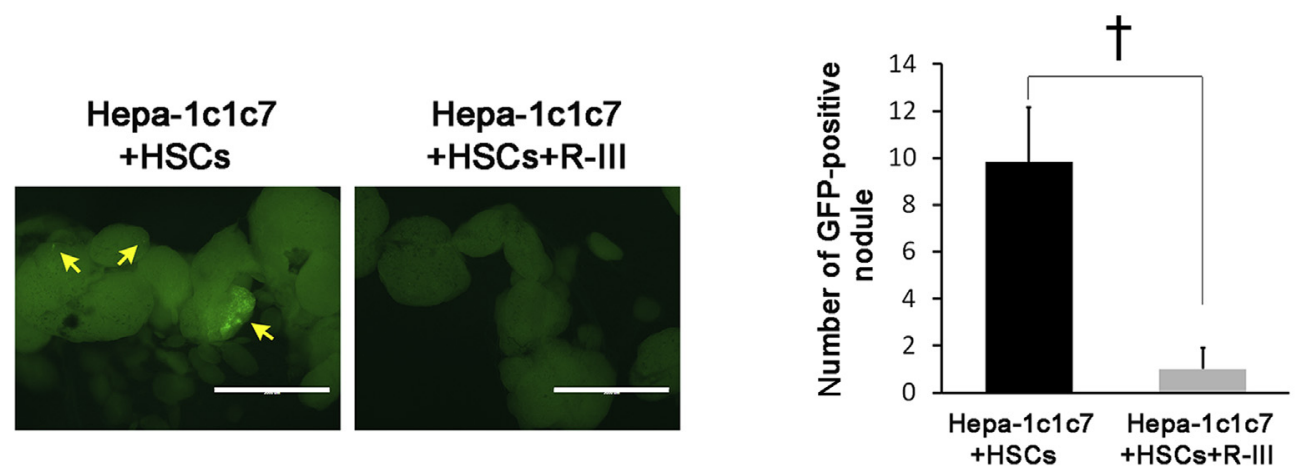

Figure 3 R-III inhibits tumor progression in the orthotopic model. A: Representative images show the entire mouse and dissected organs such as gross liver and pancreas with surrounding lymph nodes. Tumor volumes were determined at 35 days after orthotopic transplantation of Hepa-1c1c7 $\left(1 \times 10^{6}\right) \pm$ hepatic stellate cells $(\mathrm{HSCS})\left(2 \times 10^{5}\right)$ (right). The black and yellow arrows indicate ascites and swollen lymph nodes, respectively. B: Fluorescence microscopy images show green fluorescence protein (GFP)-expressing Hepa-1c1c7 cells in lymph nodes near the pancreas (left, yellow arrows), and quantification of GFP-positive nodules is shown (right). Images were acquired using the EVOS FL Imaging System. A and B: Data are expressed as means \pm SD. ${ }^{\star} P<0.05$ by Kruskal-Wallis test, followed by the Dwass-Steel-Critchlow-Fligner multiple comparison. ${ }^{\dagger} P<0.05$ by Wilcoxon rank-sum test. Scale bars: $5 \mathrm{~mm}$ (A); $2 \mathrm{~mm}$ (B).

thrombospondin-2, and TIMP-4, among which 7 proteins (ADAMTS-1, endostatin, IGFBP-3, CXCL4, CXCL10, thrombospondin-2, and TIMP-4) reportedly are angiogenesis inhibitors $^{40-42}$ (Figure 5, B and C). In contrast, the secretion of monocyte chemoattractant protein-1 (MCP-1), an angiogenic chemokine, ${ }^{43}$ was decreased by R-III. Changes in the expression and secretion of proangiogenic and anti-angiogenic factors by R-III correlated with the inhibition of tumor angiogenesis and growth.

\section{Inactivation of HSC-Derived CAFs by R-III}

Immunostaining of Hepa-1c1c7+HSC orthotopically transplanted mice with antibodies against cytoglobin/stellate cell activation-associated protein (Cygb/STAP), an 

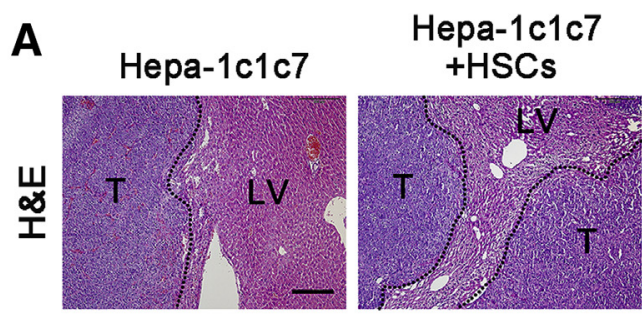

\section{Hepa-1c1c7 \\ + HSCs+R-III}
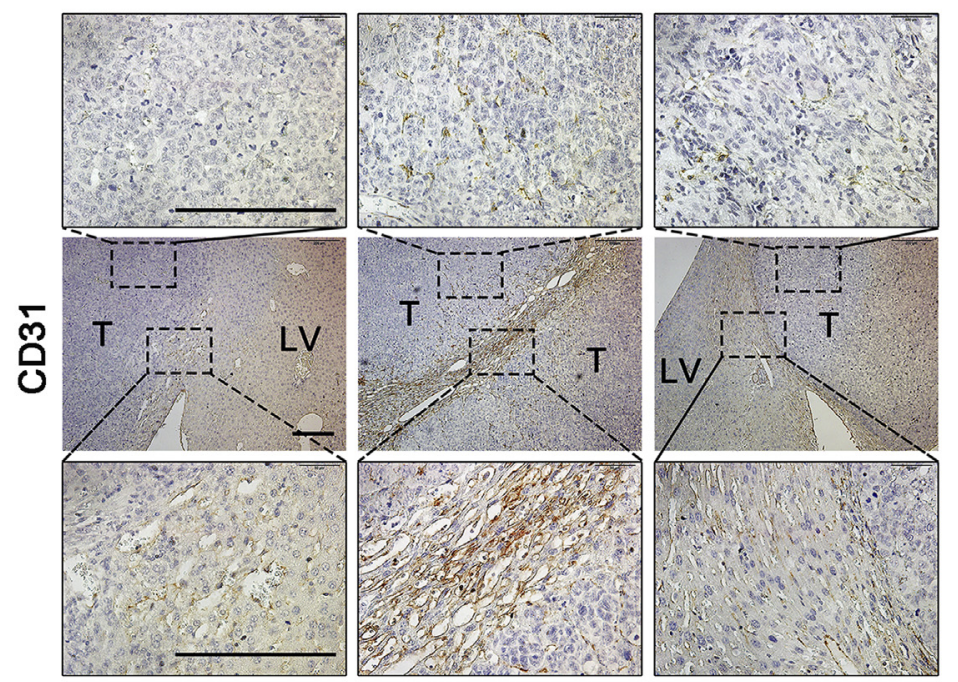

B
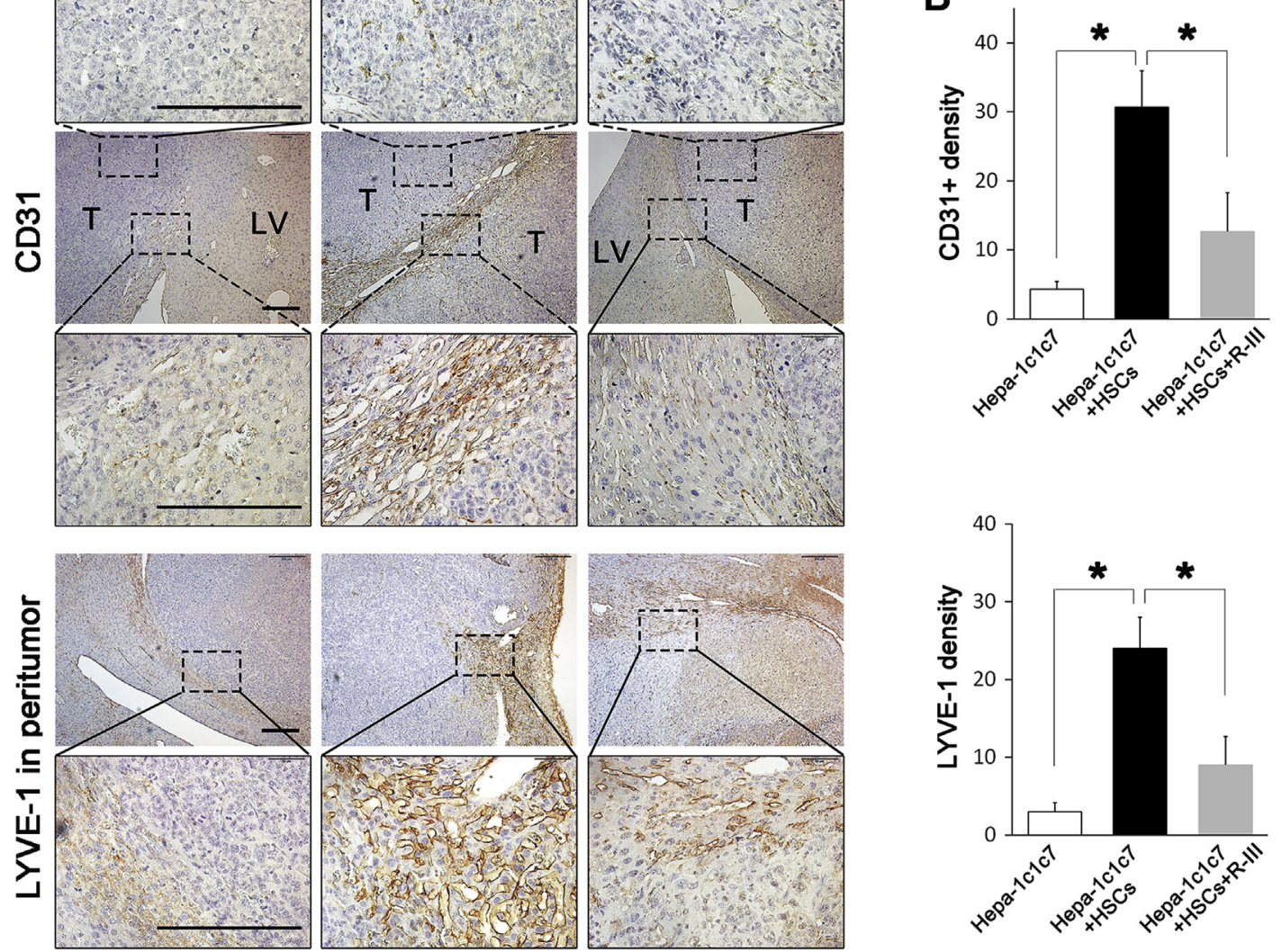

Figure 4 R-III suppresses tumor angiogenesis and lymphangiogenesis. A: Tumor sections were stained with hematoxylin and eosin (H\&E) and subjected to immunohistochemistry for CD31 and lymphatic vessel endothelial receptor-1 (LYVE-1). Selected areas (dotted boxes) of CD31 staining (intratumoral or peritumoral areas) and of LYVE-1 staining (peritumoral area) are shown above or below the original tumor sections at higher magnification. B: Semiquantitative analysis of CD31 (intratumoral area) (upper) and LYVE-1 staining (peritumoral area) (lower) is shown. Data are expressed as means \pm SD. ${ }^{*} P<0.05$ by Kruskal-Wallis test, followed by the Dwass-Steel-Critchlow-Fligner multiple comparison. Scale bar $=200 \mu \mathrm{m}$. HSC, hepatic stellate cell; LV, liver; T, tumor.

HSC marker, ${ }^{44}$ and PDGFR- $\alpha$, a marker for CAFs, ${ }^{45,46}$ led to an extensive overlap in staining, indicating that HSCs are the major contributor to the myofibroblast pool (Figure 6A). Cygb/STAP staining showed that HSCs had infiltrated the HCC stroma and peritumor tissues. Next, a series of experiments were performed to confirm the effect of R-III on HSC-derived CAFs. First, liver sections from Hepa-1c1c7+HSC orthotopically transplanted mice were subject to immunohistochemistry for $\alpha$-SMA. R-III administration reduced the intensity of $\alpha$-SMA staining in the tumor and peritumoral areas (Supplemental Figure S4). Second, primary cultures were established from orthotopic tumors (Hepa-1c1c7+HSC) and treated with R-III. As seen in Supplemental Figure S4, the staining intensity for $\alpha$-SMA was decreased significantly after R-III treatment (Figure 6B). Third, cells were isolated from orthotopic tumors (Hepa-1c1c7+HSC) by fluorescence-activated cell sorting using PDGFR- $\alpha$ antibody. R-III treatment induced the morphologic changes and the reappearance of cytoplasmic lipid droplets, a characteristic feature of pre-activated or early activated HSCs, in approximately $30 \%$ of isolated cells (Figure 6C). Thus, all of these findings suggest that R-III inactivates activated/myofibroblastic HSCs, affecting the 
A
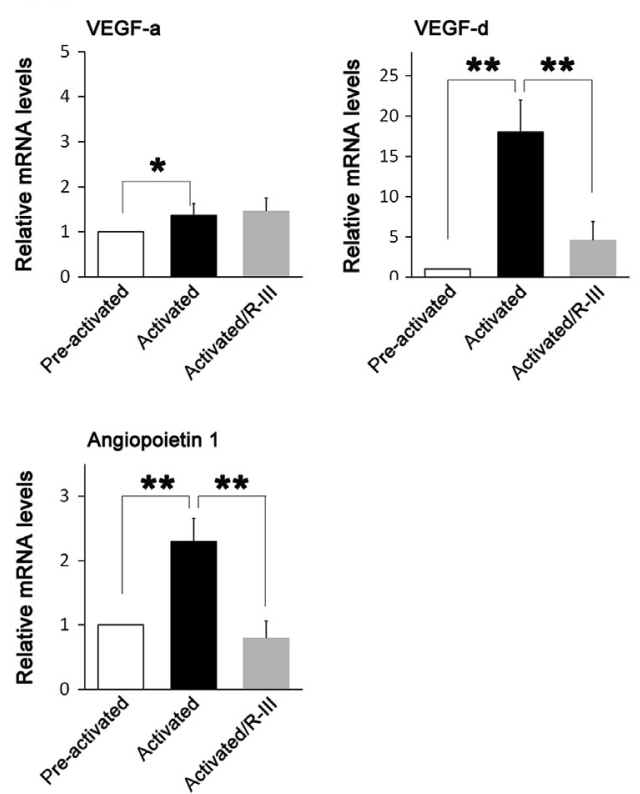

B
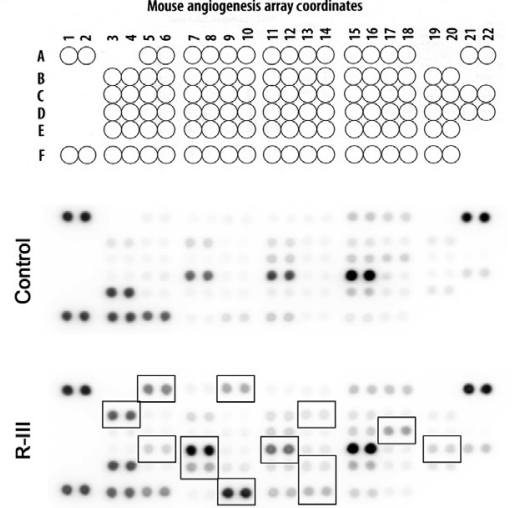

C

\begin{tabular}{|l|l|c|}
\hline \multicolumn{3}{|c|}{ Increased proteins } \\
\hline $\begin{array}{c}\text { Coordinate } \\
\text { S }\end{array}$ & \multicolumn{1}{|c|}{ Gene } & $\begin{array}{c}\text { Fold cha } \\
\text { nges }\end{array}$ \\
\hline A5,6 & ADAMTS1 & $12.5 \pm 3.5$ \\
A9,10 & angiogenin & $7.9 \pm 2.7$ \\
B3,4 & Cyr61 & $9.6 \pm 3.7$ \\
B13,14 & Endostatin & $2.1 \pm 1.0$ \\
C17,18 & IGFBP-3 & $1.9 \pm 0.5$ \\
D5,6 & CXCL10 & $3.4 \pm 1.1$ \\
D7,8 & CXCL1 & $4.5 \pm 1.5$ \\
D19,20 & MMP-9 & $5.6 \pm 1.6$ \\
E7,8 & PDGF-AA & $9.6 \pm 3.7$ \\
E13,14 & CXCL4 & $3.7 \pm 2.0$ \\
F9,10 & Thrombospondin-2 & $12.2 \pm 4.0$ \\
F13,14 & TIMP-4 & $17.5 \pm 3.5$ \\
\hline \multicolumn{3}{|c|}{ Decreased proteins } \\
\hline Coordinate & Gene & Fold cha \\
S & nges \\
\hline D11,12 & MCP-1 & $0.63 \pm 0.1$ \\
\hline \multicolumn{3}{|c|}{}
\end{tabular}

\begin{tabular}{|c|c|c|c|c|c|c|c|c|c|c|c|c|}
\hline & 2 & 4 & 5 & 8 & \begin{tabular}{l|l}
9 & 10
\end{tabular} & \begin{tabular}{l|l}
11 & 12 \\
\end{tabular} & \begin{tabular}{l|l|}
13 & 14 \\
\end{tabular} & \begin{tabular}{l|l}
15 & 16 \\
\end{tabular} & \begin{tabular}{l|l}
17 & 18 \\
\end{tabular} & \begin{tabular}{l|l}
19 & 20 \\
\end{tabular} & 21 & 22 \\
\hline A & Rot $\because \theta^{\prime}$ & & ADAMTS 1 & $\begin{array}{c:cc}\text { Ampghe } \\
\text { oul }\end{array}$ & 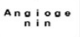 & 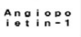 & Anotion & Fisuo & CXCLIG & & Rot: & $\because{ }^{\prime e n}$ \\
\hline B & & cyrrot & DLL4 4 & DPPIV & EGF & Endogali & Endiosta & 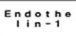 & $F G F-1$ & FGF -2 & & \\
\hline c & & FGF -7 & CX3cL1 & GM-CSF & B-EGF & HGF & I GFBP-1 & I GFBP-2 & IGFBP-3 & $12-12$ & & $-1 b$ \\
\hline D & & $12-10$ & CxcLio & $\mathrm{CxCL} 1$ & ontin & $M C P-1$ & $M I P-1 a$ & MMP - 3 & MMP - & MMP - - & IAFB & $B P-5$ \\
\hline E & & ooteopo & PD-ECGF & PDGF-AA & PDGF-BB & Pontmax & $\mathrm{CxCL} 4$ & PIGF-2 & Proinoot & Propinte & & \\
\hline $\mathrm{F}$ & Ret:ren & CXCL12 & PAI-1 & soefipin & 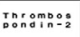 & TIMP-1 & TIMP-4 & VEGF & $V E G F-B$ & neogatov & & \\
\hline
\end{tabular}

Figure 5 R-III regulates angiogenesis-related factors in hepatic stellate cells (HSCs). A: Total RNA was isolated from the HSCs on day 1 after seeding (preactivated), and from HSCs after passage 1 (activated) with or without R-III treatment for 24 hours. Real-time PCR was used to analyze the mRNA levels of vascular endothelial growth factor (VEGF)-a, VEGF-d, and angiopoietin 1. B and C: Conditioned medium (CM) from activated HSCs treated with or without R-III was analyzed using a proteome profiler mouse angiogenesis array kit. Thirteen of 53 angiogenesis-related proteins with significant change are marked by square boxes. A and B: Data are expressed as means \pm SD. C: The quantitative densitometric data are presented as the mean fold change \pm SD of two independent experiments. $n=3 .{ }^{*} P<0.05,{ }^{*} P<0.001$ by two-way analysis of variance with the Dunnett multiple comparison test.

expression of pro-angiogenic and anti-angiogenic growth factors (Figure 6D). In summary, consistent with the in vitro results, the data obtained from the experiments using nude mice indicate that the inhibition of HSC activation abrogates the protumorigenic functions of HSCderived CAFs.
A
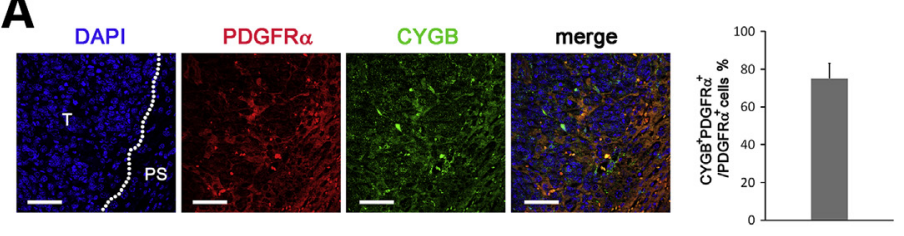

B
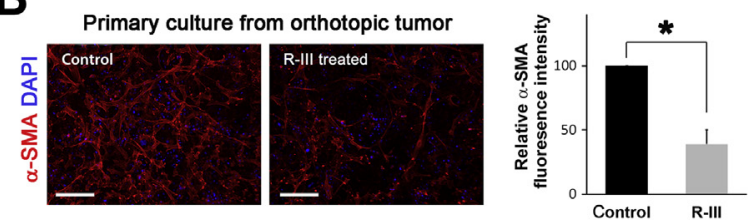

D
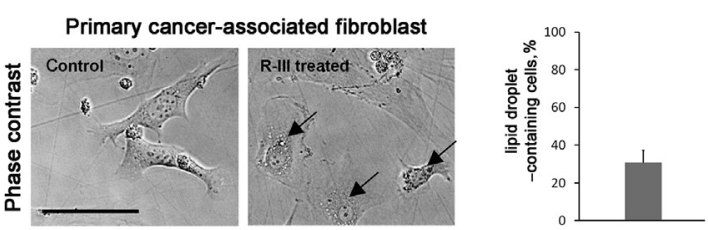

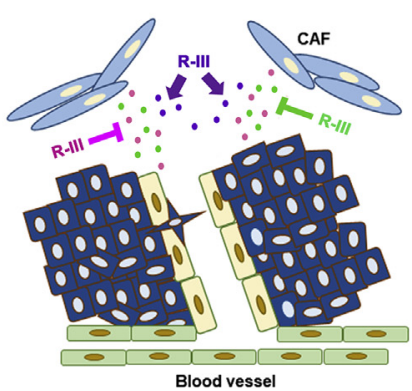

Figure 6 R-III inactivates hepatic stellate cell (HSC)-derived cancer-associated fibroblasts (CAFs). A: Liver tissues from Hepa-1c1c7+HSC-transplanted mice were analyzed using double-immunofluorescence staining for platelet-derived growth factor receptor $\alpha$ (PDGFR $\alpha$ ) (red) and cytoglobin/stellate cell activation-associated protein (Cygb/STAP) (green). The white dotted line demarcates the stromal-tumor border. Semiquantitative scoring of CYGB ${ }^{+}$PDGFR $\alpha^{+}$ double-positive cells as a percentage of PDGFR $\alpha$-stained cells is shown on the right. B: Primary cultures from orthotopic tumors were treated with R-III and analyzed by immunofluorescence. C: Cells were isolated from orthotopic tumors (Hepa-1c1c7+HSC) by fluorescence-activated cell sorting using the PDGFR- $\alpha$ antibody and treated with R-III. R-III induces phenotypic conversion from myofibroblast to fat-storing cells (arrows). D: Proposed model for the anticancer effect of R-III. R-III inactivates HSC-derived CAFs, thus inhibiting the secretion of angiogenic and growth factors. B: Data are expressed as means \pm SD. ${ }^{*} P<0.01$ by Wilcoxon rank-sum test. Scale bar $=200 \mu \mathrm{m}$. HCC, hepatocellular carcinoma; PS, peritumoral stroma; T, tumor. 


\section{Discussion}

Previous studies have shown that stromal HSCs promote tumor progression. The present study further supports the effect of activated/myofibroblastic HSCs on HCC progression in vitro and in vivo. The rapid growth of malignant HCC cells requires adequate nutritional supply and active angiogenesis. ${ }^{47}$ The blood vessel density in the tumors derived from mice co-transplanted with HSCs was higher compared with that in the tumors originated from Hepa1c1c6 cells alone. Activated HSCs reportedly promote tumor angiogenesis by secreting a number of angiogenic factors, thereby creating a protumorigenic microenvironment. The results of this study showed that angiogenic factors, such as VEGF-d, PDGF-d, angiopoietin-1, and CXCL12, were significantly up-regulated during HSC activation (Figures $1 \mathrm{E}$ and 5A). CXCL12 is a chemokine that recruits circulating endothelial precursor cells, and is involved in tumor growth, metastasis, angiogenesis, and cancer cell-TME interactions. ${ }^{36}$

On the other hand, treatment of activated HSCs with R-III decreased expression of these angiogenic factors, decreased secretion of MCP-1, and increased secretion of antiangiogenic factors, which correlated with a reduction in vascular density and tumor growth delay. Because R-III did not affect Hepa-1c1c7 cells directly, the in vivo antitumor activity of R-III likely was attributed to its action on activated/myofibroblastic HSCs.

Quiescent SCs store retinoids in the form of retinyl esters in cytoplasmic lipid droplets. When the lipid droplets are lost rapidly during SC activation, a portion of their retinoid contents are likely released and metabolized into retinaldehyde and retinoic acid. The role of retinoids in HSC activation has been proposed, but previous reports regarding the effects of exogenous retinoids on HSCs and liver fibrosis were controversial. ${ }^{48}$ However, Lee et $\mathrm{al}^{19}$ reported that endogenous retinoic acid was involved in the activation of HSCs and that R-III inhibited HSC activation by sequestering retinoic acid. Retinoic acid sequestration in turn caused a dramatic increase in IL- $1 \beta$ expression, resulting in the inhibition of Smad3 nuclear translocation in HSCs. ${ }^{21}$ This shows that R-III can influence gene expression in HSCs. However, further study is needed to address how R-III affects the expression of pro-angiogenic and anti-angiogenic factors.

Extensive necrosis was found in the subcutaneous tumors harvested from Hepa-1c1c7+HSC+RIII groups compared with the other two groups namely, the Hepa-1c1c7-alone group and the Hepa-1c1c7+HSC group. Necrotic tissue is characterized by cell death with or without loss of structural integrity (coagulative necrosis versus liquefactive necrosis). Thus, tumors undergoing necrosis can undergo a reduction in tumor weight, caused by cell death, membrane disruption, and loss of nuclear and cytoplasmic content, without loss of tumor volume. ${ }^{49}$ It is reasonable to conclude that the difference in tumor weights, without a concomitant change in tumor size, was caused by the extensive necrosis in the Hepa$1 \mathrm{c} 1 \mathrm{c} 7+\mathrm{HSC}+\mathrm{R}-\mathrm{III}$ tumors. This necrosis represents tumor cell death, and eventual resorption of the tumor debris is expected to occur at a later stage in tumor evolution, at a time point beyond the scope of the current experimental protocol.

The expression of VEGF-d, which enhances lymphangiogenesis and lymphatic metastasis, ${ }^{50,51}$ was up-regulated significantly during HSC activation and was down-regulated by R-III. PDGF-d is also reportedly involved in tumor lymphangiogenesis. ${ }^{52}$ The results of this study showed that the expression profile of VEGF-d and PDGF-d correlated with peritumoral lymphatic density and lymph node metastasis. As previously described, ${ }^{19}$ mice showed no apparent side effects after receiving R-III.

Most therapeutic strategies against cancer have focused on targeting tumor cells directly, but, recently, strategies also have been developed to target the TME. Because stromal cells are indispensable for tumor angiogenesis, antiangiogenic therapies must be aimed at targeting stromal cells as well as cancer cells. This study supports that stromal HSCs contribute significantly to HCC angiogenesis, and therefore suggests that inhibition of HSC-induced tumor angiogenesis may be useful for controlling tumors. The current study supports the presence of a protumor crosstalk between cancer cells and activated HSCs, which represents an attractive therapeutic target for anticancer therapy. Moreover, because SCs are also present in extrahepatic organs such as pancreas, kidneys, intestines, and lungs, ${ }^{53}$ their potential contribution to cancer progression should be investigated.

\section{Acknowledgments}

We thank Boram Lee, Esther Yang, and Ji Eun Song for technical assistance, and Dr. Norifumi Kawada for providing the cytoglobin/stellate cell activation-associated protein/STAP antibody.

\section{Author Contributions}

J.O. conceived and supervised the study; M.-J.K. and J.O. designed the experiments and wrote the manuscript; M.J.K., S.L., U.J., C.M., H.P., and J.W.M. performed the experiments and collected data; and W.G.S.-S., Y.-S.K., S.H.P., and J.O. analyzed and interpreted data.

\section{Supplemental Data}

Supplemental material for this article can be found at http://doi.org/10.1016/j.ajpath.2021.08.004.

\section{References}

1. Quail DF, Joyce JA: Microenvironmental regulation of tumor progression and metastasis. Nat Med 2013, 19:1423-1437 
2. Gomes FG, Nedel F, Alves AM, Nör JE, Tarquinio SB: Tumor angiogenesis and lymphangiogenesis: tumor/endothelial crosstalk and cellular/microenvironmental signaling mechanisms. Life Sci 2013, 92:101-107

3. Li H, Fan X, Houghton J: Tumor microenvironment: the role of the tumor stroma in cancer. J Cell Biochem 2007, 101:805-815

4. Santi A, Kugeratski FG, Zanivan S: Cancer associated fibroblasts: the architects of stroma remodeling. Proteomics 2018, 18:e1700167

5. Apte MV, Wilson JS, Lugea A, Pandol SJ: A starring role for stellate cells in the pancreatic cancer microenvironment. Gastroenterology 2013, 144:1210-1219

6. Kang N, Gores GJ, Shah VH: Hepatic stellate cells: partners in crime for liver metastases? Hepatology 2011, 54:707-713

7. Amann T, Bataille F, Spruss T, Muhlbauer M, Gabele E, Scholmerich J, Kiefer P, Bosserhoff AK, Hellerbrand C: Activated hepatic stellate cells promote tumorigenicity of hepatocellular carcinoma. Cancer Sci 2009, 100:646-653

8. Vonlaufen A, Joshi S, Qu C, Phillips PA, Xu Z, Parker NR, Toi CS, Pirola RC, Wilson JS, Goldstein D, Apte MV: Pancreatic stellate cells: partners in crime with pancreatic cancer cells. Cancer Res 2008, 68:2085-2093

9. Friedman SL: Hepatic stellate cells: protean, multifunctional, and enigmatic cells of the liver. Physiol Rev 2008, 88:125-172

10. Tsuchida T, Friedman SL: Mechanisms of hepatic stellate cell activation. Nat Rev Gastroenterol Hepatol 2017, 14:397-411

11. Puche JE, Saiman Y, Friedman SL: Hepatic stellate cells and liver fibrosis. Compr Physiol 2013, 3:1473-1492

12. Thompson AI, Conroy KP, Henderson NC: Hepatic stellate cells: central modulators of hepatic carcinogenesis. BMC Gastroenterol 2015, 15:63

13. Apte MV, Haber PS, Applegate TL, Norton ID, McCaughan GW, Korsten MA, Pirola RC, Wilson JS: Periacinar stellate shaped cells in rat pancreas: identification, isolation, and culture. Gut 1998, 43: $128-133$

14. Erkan M, Adler G, Apte MV, Bachem MG, Buchholz M, Detlefsen S, Esposito I, Friess H, Gress TM, Habisch HJ, Hwang RF, Jaster R, Kleeff J, Kloppel G, Kordes C, Logsdon CD, Masamune A, Michalski CW, Oh J, Phillips PA, Pinzani M, Reiser-Erkan C, Tsukamoto H, Wilson J: StellaTUM: current consensus and discussion on pancreatic stellate cell research. Gut 2012, 61:172-178

15. Evans TW: Review article: albumin as a drug-biological effects of albumin unrelated to oncotic pressure. Aliment Pharmacol Ther 2002, 16(Suppl 5):6-11

16. Kim N, Yoo W, Lee J, Kim H, Lee H, Kim YS, Kim DU, Oh J: Formation of vitamin A lipid droplets in pancreatic stellate cells requires albumin. Gut 2009, 58:1382-1390

17. Choi S, Park S, Kim S, Lim C, Kim J, Cha DR, Oh J: Recombinant fusion protein of albumin-retinol binding protein inactivates stellate cells. Biochem Biophys Res Commun 2012, 418:191-197

18. Kawaguchi R, Yu J, Honda J, Hu J, Whitelegge J, Ping P, Wiita P, Bok D, Sun H: A membrane receptor for retinol binding protein mediates cellular uptake of vitamin A. Science 2007, 315:820-825

19. Lee H, Jeong H, Park S, Yoo W, Choi S, Choi K, Lee MG, Lee M, Cha D, Kim YS, Han J, Kim W, Park SH, Oh J: Fusion protein of retinol-binding protein and albumin domain III reduces liver fibrosis. EMBO Mol Med 2015, 7:819-830

20. Cha JJ, Mandal C, Ghee JY, Yoo JA, Lee MJ, Kang YS, Hyun YY, Lee JE, Kim HW, Han SY, Han JY, Chung AY, Yoon DW, Rhyu IJ, Oh J, Cha DR: Inhibition of renal stellate cell activation reduces renal fibrosis. Biomedicines 2020, 8:431

21. Park JH, Kim J, Choi SY, Lee B, Lee JE, Park H, Moon JW, Park SH, Lee JM, Lee HS, Oh J: Albumin inhibits the nuclear translocation of Smad3 via interleukin-1beta signaling in hepatic stellate cells. Sci Rep 2021, 11:3196

22. Committee for the Update of the Guide for the Care and Use of Laboratory Animals; National Research Council: Guide for the Care and Use of Laboratory Animals. Eighth Edition. Washington, DC, National Academies Press, 2011

23. Reiberger $T$, Chen $Y$, Ramjiawan RR, Hato $T$, Fan $C$, Samuel R, Roberge S, Huang P, Lauwers GY, Zhu AX, Bardeesy N, Jain RK, Duda DG: An orthotopic mouse model of hepatocellular carcinoma with underlying liver cirrhosis. Nat Protoc 2015, 10:1264-1274

24. Min HS, Kim JE, Lee MH, Song HK, Kang YS, Lee MJ, Lee JE, Kim HW, Cha JJ, Chung YY, Hyun YY, Han JY, Cha DR: Dipeptidyl peptidase IV inhibitor protects against renal interstitial fibrosis in a mouse model of ureteral obstruction. Lab Invest 2014, 94:598-607

25. Seki T, Hosaka K, Lim S, Fischer C, Honek J, Yang Y, Andersson P, Nakamura M, Näslund E, Ylä-Herttuala S, Sun M, Iwamoto H, Li X, Liu Y, Samani NJ, Cao Y: Endothelial PDGF-CC regulates angiogenesis-dependent thermogenesis in beige fat. Nat Commun 2016, 7:12152

26. Min JH, Lee CH, Ji YW, Yeo A, Noh H, Song I, Kim EK, Lee HK: Activation of Dl14/Notch signaling and hypoxia-inducible factor-1 alpha facilitates lymphangiogenesis in lacrimal glands in dry eye. PLoS One 2016, 11:e0147846

27. Mourcin F, Breton C, Tellier J, Narang P, Chasson L, Jorquera A, Coles M, Schiff C, Mancini SJ: Galectin-1-expressing stromal cells constitute a specific niche for pre-BII cell development in mouse bone marrow. Blood 2011, 117:6552-6561

28. Jeansson M, Gawlik A, Anderson G, Li C, Kerjaschki D, Henkelman M, Quaggin SE: Angiopoietin-1 is essential in mouse vasculature during development and in response to injury. J Clin Invest 2011, 121:2278-2289

29. Sharon Y, Alon L, Glanz S, Servais C, Erez N: Isolation of normal and cancer-associated fibroblasts from fresh tissues by fluorescence activated cell sorting (FACS). J Vis Exp 2013, 71:e4425

30. Rockey DC, Boyles JK, Gabbiani G, Friedman SL: Rat hepatic lipocytes express smooth muscle actin upon activation in vivo and in culture. J Submicrosc Cytol Pathol 1992, 24:193-203

31. Friedman SL, Roll FJ, Boyles J, Bissell DM: Hepatic lipocytes: the principal collagen-producing cells of normal rat liver. Proc Natl Acad Sci U S A 1985, 82:8681-8685

32. Buniatian GH: Stages of activation of hepatic stellate cells: effects of ellagic acid, an inhibiter of liver fibrosis, on their differentiation in culture. Cell Prolif 2003, 36:307-319

33. Lin N, Chen Z, Lu Y, Li Y, Hu K, Xu R: Role of activated hepatic stellate cells in proliferation and metastasis of hepatocellular carcinoma. Hepatol Res 2015, 45:326-336

34. Zhao W, Zhang L, Yin Z, Su W, Ren G, Zhou C, You J, Fan J, Wang X: Activated hepatic stellate cells promote hepatocellular carcinoma development in immunocompetent mice. Int $\mathrm{J}$ Cancer 2011, 129:2651-2661

35. Byun HO, Lee YK, Kim JM, Yoon G: From cell senescence to agerelated diseases: differential mechanisms of action of senescenceassociated secretory phenotypes. BMB Rep 2015, 48:549-558

36. Meng W, Xue S, Chen Y: The role of CXCL12 in tumor microenvironment. Gene 2018, 641:105-110

37. Christiansen A, Detmar M: Lymphangiogenesis and cancer. Genes Cancer 2011, 2:1146-1158

38. Taura K, De Minicis S, Seki E, Hatano E, Iwaisako K, Osterreicher CH, Kodama Y, Miura K, Ikai I, Uemoto S, Brenner DA: Hepatic stellate cells secrete angiopoietin 1 that induces angiogenesis in liver fibrosis. Gastroenterology 2008, 135:1729-1738

39. Wang Z, Ahmad A, Li Y, Kong D, Azmi AS, Banerjee S, Sarkar FH: Emerging roles of PDGF-D signaling pathway in tumor development and progression. Biochim Biophys Acta 2010, 1806: $122-130$

40. Albini A, Tosetti F, Li VW, Noonan DM, Li WW: Cancer prevention by targeting angiogenesis. Nat Rev Clin Oncol 2012, 9:498-509

41. Keeley EC, Mehrad B, Strieter RM: Chemokines as mediators of tumor angiogenesis and neovascularization. Exp Cell Res 2011, 317 : 685-690 
42. Kim JH, Choi DS, Lee OH, Oh SH, Lippman SM, Lee HY: Antiangiogenic antitumor activities of IGFBP-3 are mediated by IGFindependent suppression of Erk1/2 activation and Egr-1-mediated transcriptional events. Blood 2011, 118:2622-2631

43. Hong KH, Ryu J, Han KH: Monocyte chemoattractant protein-1induced angiogenesis is mediated by vascular endothelial growth factor-A. Blood 2005, 105:1405-1407

44. Motoyama H, Komiya T, Thuy le TT, Tamori A, Enomoto M, Morikawa H, Iwai S, Uchida-Kobayashi S, Fujii H, Hagihara A, Kawamura E, Murakami Y, Yoshizato K, Kawada N: Cytoglobin is expressed in hepatic stellate cells, but not in myofibroblasts, in normal and fibrotic human liver. Lab Invest 2014, 94:192-207

45. Togo S, Polanska UM, Horimoto Y, Orimo A: Carcinoma-associated fibroblasts are a promising therapeutic target. Cancers 2013, 5:149-169

46. Erez N, Truitt M, Olson P, Arron ST, Hanahan D: Cancer-associated fibroblasts are activated in incipient neoplasia to orchestrate tumorpromoting inflammation in an NF-kappaB-dependent manner. Cancer Cell 2010, 17:135-147

47. Russo M, Giavazzi R: Anti-angiogenesis for cancer: current status and prospects. Thromb Res 2018, 164(Suppl 1):S3-S6
48. Zhou TB, Drummen GP, Qin YH: The controversial role of retinoic acid in fibrotic diseases: analysis of involved signaling pathways. Int J Mol Sci 2012, 14:226-243

49. Kumar V, Abbas AK, Aster JC: Robbins \& Cotran Pathologic Basis of Disease. Amsterdam: Elsevier, 2021

50. Stacker SA, Caesar C, Baldwin ME, Thornton GE, Williams RA, Prevo R, Jackson DG, Nishikawa S, Kubo H, Achen MG: VEGF-D promotes the metastatic spread of tumor cells via the lymphatics. Nat Med 2001, 7:186-191

51. Thelen A, Scholz A, Benckert C, von Marschall Z, Schroder M, Wiedenmann B, Neuhaus P, Rosewicz S, Jonas S: VEGF-D promotes tumor growth and lymphatic spread in a mouse model of hepatocellular carcinoma. Int J Cancer 2008, 122:2471-2481

52. Jitariu AA, Cimpean AM, Kundnani NR, Raica M: Platelet-derived growth factors induced lymphangiogenesis: evidence, unanswered questions and upcoming challenges. Arch Med Sci 2015, 11:57-66

53. Nagy NE, Holven KB, Roos N, Senoo H, Kojima N, Norum KR, Blomhoff R: Storage of vitamin A in extrahepatic stellate cells in normal rats. J Lipid Res 1997, 38:645-658 